\title{
Application of Security System Legal Documents Reviewer Letters Using Blockchain Technology
}

\author{
Sindy Amelia', Oktaviana Widya Ningrum ${ }^{2}$ \\ University Of Raharja ${ }^{1,2}$ \\ Jl. Jenderal Sudirman No.40, RT.002/RW.006, Cikokol, Kec. Tangerang, Kota Tangerang, \\ Banten 15117,2, \\ e-mail: sindy.amelia@raharja.info' ${ }^{1}$, oktaviana@raharia.info $^{2}$
}

Oktaviana, N.W, Amelia.S, Application of Security System Legal Documents Reviewer Letters Using Blockchain.

Blockchain Frontier Technology (B-Front), 1(2), 65-73.

DOI: https://journal.pandawan.id/b-front/article/view/37

\begin{abstract}
the popularity of blockchain technology has been widely used in aspects of life in various fields and industries. Because previously blockchain technology was used as crypto or known as digital currency which has developed towards technology and digital is growing rapidly. Where the use of blockchain technology is a new innovation that is increasingly developing in data security systems to suit the times and become one of the modern technologies in the world of education. However, nowadays there are often crimes in the illegal falsification of reviewer letters that can be carried out by irresponsible people for personal interests and can harm the parties concerned. For that we need a data security technology without the need for a third party called blockchain that can maintain the authenticity of the reviewer's letter from the criminal actions of irresponsible parties in forging intentionally or unintentionally. Raharja College has applied blockchain technology to a tool called $A B C$ (data security) and has been implemented on the adimas website which has been going on for two years. Blockchain technology has an encryption hash code or a unique code that is a sign that a letter that has been verified with the blockchain can be seen as different from the original or fake. Because blockchain technology has a level of data security with a block system that is interconnected and has an encryption hash code. This paper uses the literature study method by looking at previous papers with the same theme. This research has the aim that future researchers can produce new innovations in improving data security and improving the quality of technology that can produce new findings in more modern data security systems.
\end{abstract}

Keywords: Blockchain technology, reviewer letter, $A B C$ Blockchain

\section{Introduction}

Data falsification is a crime that can harm certain parties due to the actions of third parties who take advantage of data falsification to be traded or used personally. For this reason, technology is needed that can store data permanently and has a modern level of data security so that it cannot be changed and only seen. Blockchain technology is a technology that is currently popular in various fields in data security. Because the use of blockchain technology is quite easy to apply and the system offered is unique in it without the need for a third party. The use of blockchain is often used in the field of education regarding certificates. From this usage, it can be seen that the use of blockchain is growing in its application in documents or review letters in order to avoid third-party forgery and the difference between the original and the fake, 
called abc. Blockert itself has a function in the blockchain that has transparency and accountability that is used for storage. Blockchain technology is called the ledger and is known as fifth evolution, namely a development of computers into computers where blockchain has a data structure that can make offline books digital.

The block chain with cryptographic elements is a technological revolution with the innovation that was discovered in 1991 by Stuart Haber and W. Scoot Stornetta. known as blockchain technology at this time. Satoshi Nakamoto was a blockchain technology figure in 2008 which was used for bitcoin, and the following year, precisely in 2009 blockchain technology developed and has a network that is used for transactions. In 2014 blockchain technology is known as blockchain 2.0 which has been further developed by incorporating a programming language known as smart contact. The smart contact can make transactions without the need for a third party, the process in the smart contact is a transaction between the two parties concerned and can issue a bill (receipt) regarding what transactions were carried out. Singapore developed the blockchain technology in a company in 2016, the company was named with IBM as one of the research centers with the innovation of the automated voting system and the technology is growing with other new innovations throughout the year.

Blockchain technology is divided into three parts, including: (1) Public Blockchain, a technology with a wide range of distribution and native tokens used in work, (2) Permissive Blockchain, which is a condition for developing a system in accordance with the requirements in the blockchain technology network, (3) Private blockchain, is a technology that does not require a native token but has a small scale of use and is the favorite use for consortium participants.
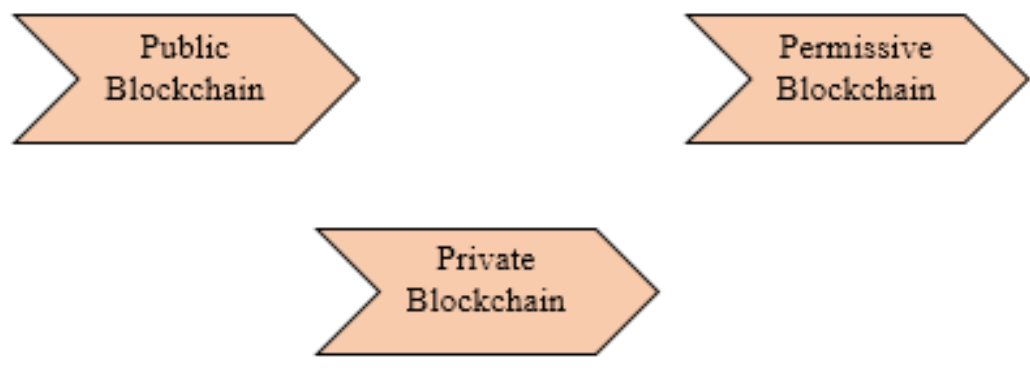

Figure 1. The blockchain technology section.

Not only that, blockchain turns out to have three characteristics including: (1) Not centralized or decentralized, it is a system that runs uncontrolled and the server in the blockchain is not located in it because there is a hash code and contains blocks to perform transaction. (2) immutable or immutable, blockchain technology on a platform cannot be lost and remains securely stored, because the combination of hash pointer data has gone to the block and the creation of a connected chain, and (3) open-source and transparent, means that the data is visible and visible. can be accessed by others, but the accessor cannot do anything because it has been verified with an encryption code on blockchain technology so that it can know that the data is real or fake. 


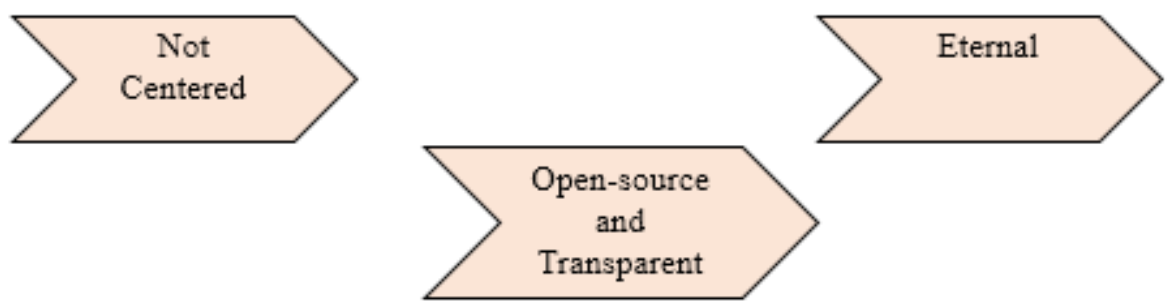

Figure 2. The nature of blockchain Blockchain

technology has seven advantages which can be seen in the image below:
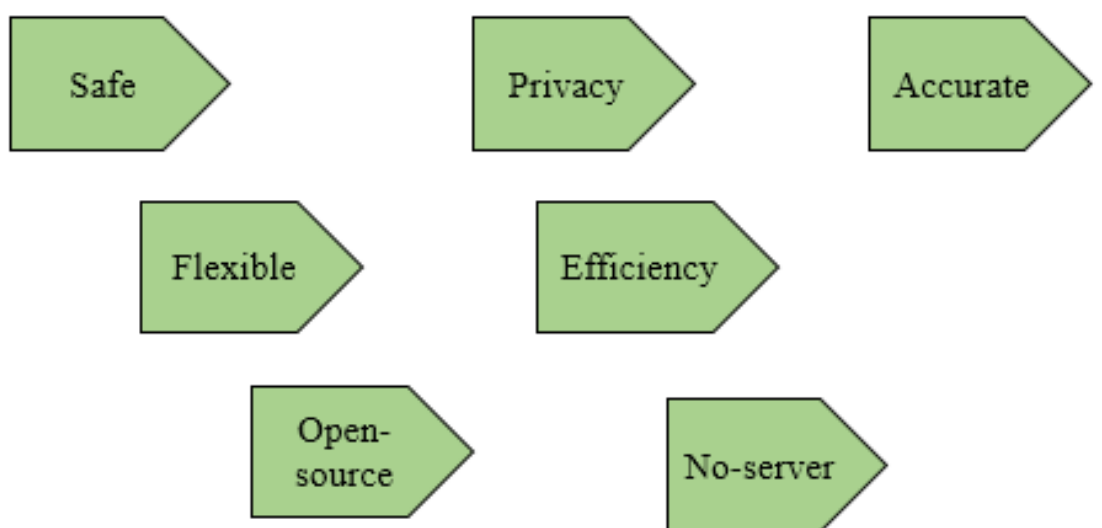

\section{Efficiency}

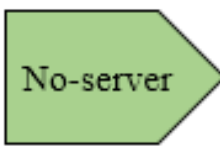

Figure 3. The advantages of blockchain

Not only that, blockchain turns out to have three characteristics including: (1) Not centralized or decentralized, it is a system that runs uncontrolled and the server in the blockchain is not located in it because there is a hash code and contains blocks to perform transaction. (2) immutable or immutable, blockchain technology on a platform cannot be lost and remains securely stored, because the combination of hash pointer data has gone to the block and the creation of a connected chain, and (3) open-source and transparent, means that the data is visible and visible. can be accessed by others, but the accessor cannot do anything because it has been verified with an encryption code on blockchain technology so that it can know that the data is real or fake.

From the picture above, it can be explained that blockchain technology has advantages, namely: (1) Safe, namely blockchain technology has hash codes and blocks that have irreversible properties (cannot be changed) by parties by other parties, because each block on the blockchain will interconnected with a hash which is verified automatically when a new transaction occurs and is recorded in a new block. (2) Flexibility with the intention that the technology has storage capabilities that can adjust data storage when implementing it in certain fields. (3) Open-source is software for building blockchain technology, where anyone who has access can change the coding in it and in accordance with the conditions set in making changes by the developer. (4) Privacy has a meaning such as hiding user's personal data, not hiding 
account names and hiding secrets to the public because the blockchain itself runs like a website that can be seen by all parties. (5) Efficiency, blockchain itself can shorten the time in carrying out a transaction that is only needed in minutes. (6) No-server, means that the technology does not have a central server on the data contained in a network node, because updates that occur in a new block are made to one node containing the block, so that blockchain technology is free from crimes such as hackers. (7) Accurate, the data contained in blockchain technology is verified by thousands of nodes when carrying out transactions, thereby reducing errors due to the absence of human intervention.

\section{Method}

This research uses the literature study method by looking for ten papers from previous studies and of course in accordance with the research theme. The application of blockchain technology in crowdfunding is one of the new innovations used for data security when conducting transactions and transparency to avoid data falsification from other parties. Blockchain technology has been used in e-commerce to make it easier for students, lecturers and other parties to make transactions so that transaction times are easier and more efficient and can check product authenticity, build systems such as tracking and identity management.

Digital data storage is known as blockchain technology with multi servers that have been used by universities in processing relevant data. This study uses blockchain as a medium to see the authenticity of a diploma, so that companies can check directly on the diplomas of employees who work at the company, because diplomas are often used for buying and selling between parties in personal interests to the detriment of others. The implementation of blockchain technology on certificates by using an encryption code certainly increases the security system on the certificate to avoid doubling the certificate.

Content logging of course requires a system that can secure the content from crime, by storing the content on blockchain technology so that its authenticity is maintained from the creator and stored properly without any errors. Changing student personal data, such as diplomas and certificates can be easily faked especially in paper form, therefore technology offers digital data storage and has a unique code (script) in it. The chain of blocks that are connected by hashes and run in the same direction are useful for data processing so that the data is decentralized and transparent so that information from the Kendal city government can be known and trusted by residents.

Usernames and passwords are data that can be hacked by hackers to commit crimes, for that the application of blockchain technology is used to be safe from crime by testing the burp suite. Distributed record keeping evokes educational confidence in the application of blockchain technology so that it is used in learning, converting paper certificates to digital and can secure intellectuality. Trust is the main key in the application of blockchain technology in various fields so that it is used in gamification with transpirational properties and has integrity which results in no need for third parties when processing data.

From the ten research papers above, it can be concluded that blockchain technology has been used in various sectors to improve security systems in order to avoid duplication, manipulation and counterfeiting on a regular basis in order to achieve personal gain without thinking that the parties concerned can be harmed. And blockchain technology has an encryption hans code that is connected to the block against nodes connected to the network so that there is a verified block chain so that the data has a unique code so that it can be checked for authenticity. .

\section{Results and Discussion}

In its application, Blockchain technology is not only used in the banking sector and the hospital sector, but this Blockchain can also be used in the field of publishing scientific papers. The application of Blockchain in reviewer letters is intended to avoid the act of forging letters from irresponsible parties.

In Blockchain technology there are hashes and encryption, the hash itself is usually a digital signature that has a value of 128 bits long while Encryption is a process that changes a 
code from an understandable (plaintext) to an incomprehensible code (ciphertext). Hash itself has many types, namely, MD4, MD5, SHA-1, SHA-256, SHA-512, Alphabet Blockchain (ABC) using the hash type SHA-256.

Each type of hash has different characteristics, for example the SHA-256 hash has a hash characteristic that starts with a $\$ 5 \$$ sign and then continues with a salt of 8 randomly arranged characters, for example " 12345678 " followed by the character " $\$$ " and then continued by hash, has a length of 55 characters for example: $\$ 5 \$ 12345678$ jiBWLgeYZbSvREnuBr5s3gp13vqi.

Because the reviewer's letter is included in one of the important documents related to lecturer certification, if there is a forgery then it is certainly very dangerous. The reviewer's letter is said to be authenticated. Blockchain has an encryption code or hash code in it at the time of verification. If the reviewer's letter does not contain an encryption or hash code, it can be said that the authentication process has not been successful.

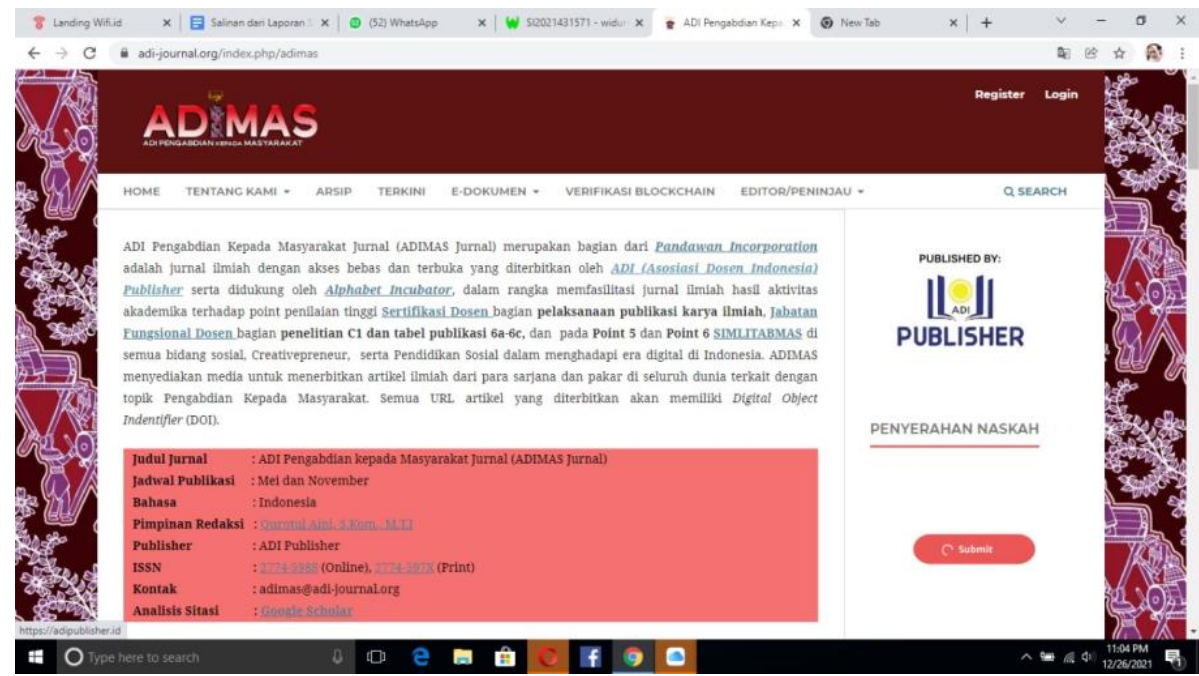

Figure 4. Home site ADIMAS Jurnal

\section{Verifikasi Blockchain}

ADIMAS jurnal saat ini sudah menerapkan sistem blockchain pada setiap dokumennya. Yang dapat diverifikasi melalui Alphabet Blockhain. Klik icon di bawah untuk menuju halaman verifikasi. Apabila terdapat kendala dapat melihat video dibawah.

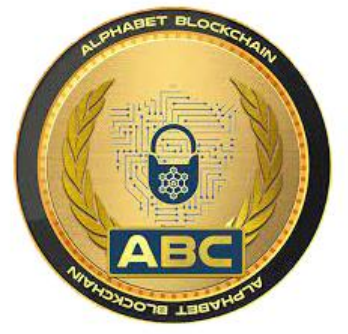

Figure 5. Sub menu ADIMAS 
On the adimas sub menu there is a link that goes directly to the $A B C$ Blockchain platform and there is also a video tutorial where there is this video in order to make it easier for users who want to authenticate with the ABC Blockchain. As well as links to facilitate user access without having to search hard.

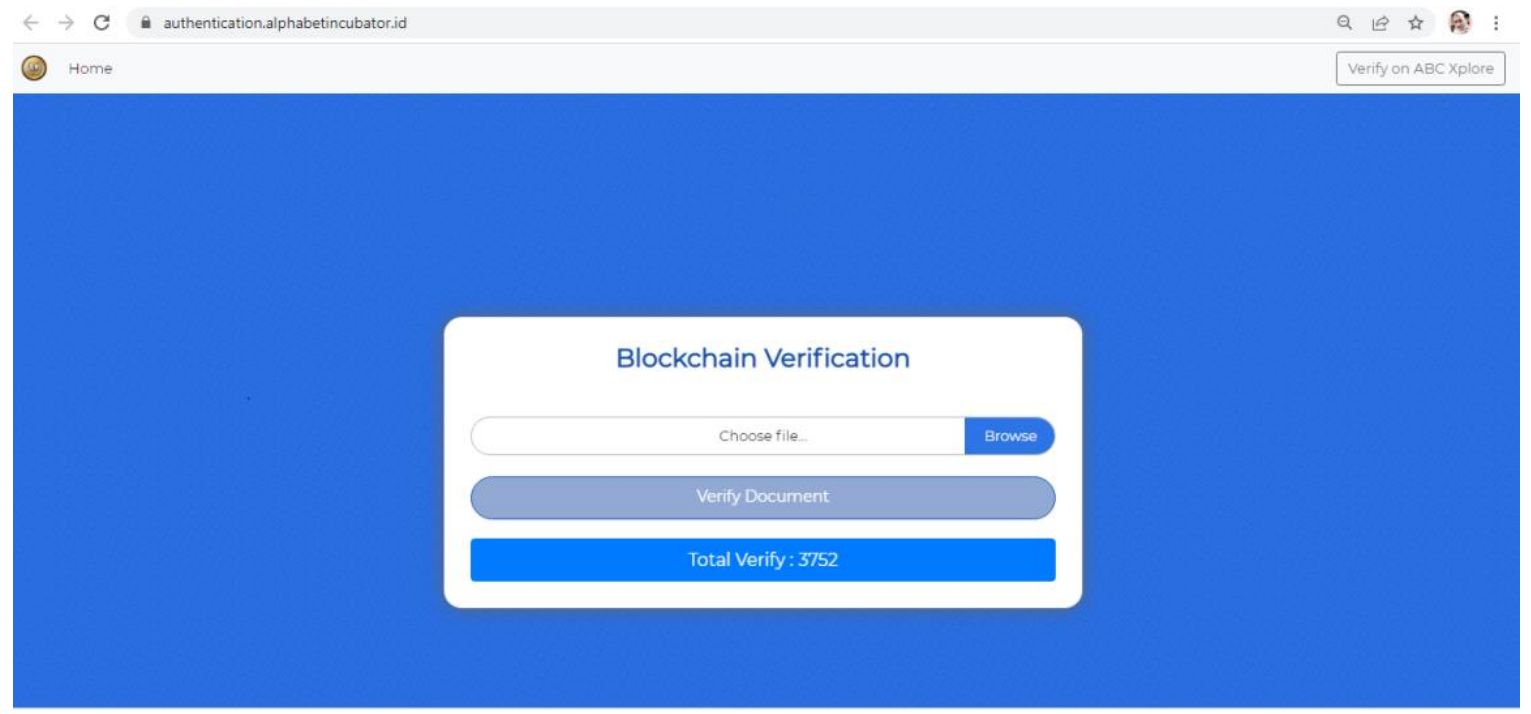

Figure 6.Home site ABC Blockchain

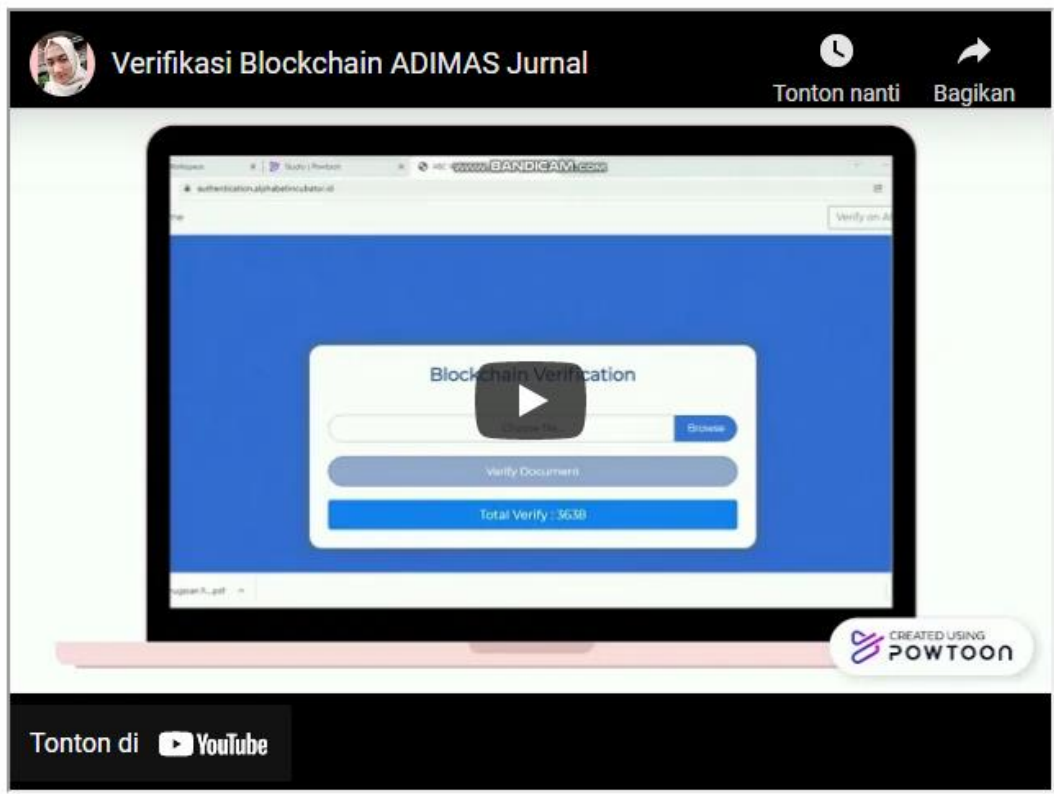

Figure 7. Video tutorial on site ADIMAS

It is in the picture above where ADIMAS Journal has started to implement Blockchain technology as a medium for securing legal documents, it can be seen that there is an additional menu in the form of Blockchain verification. Where the menu aims to verify a document whether 
the document is original or not and also check whether the Blockchain has been successfully applied to the document.

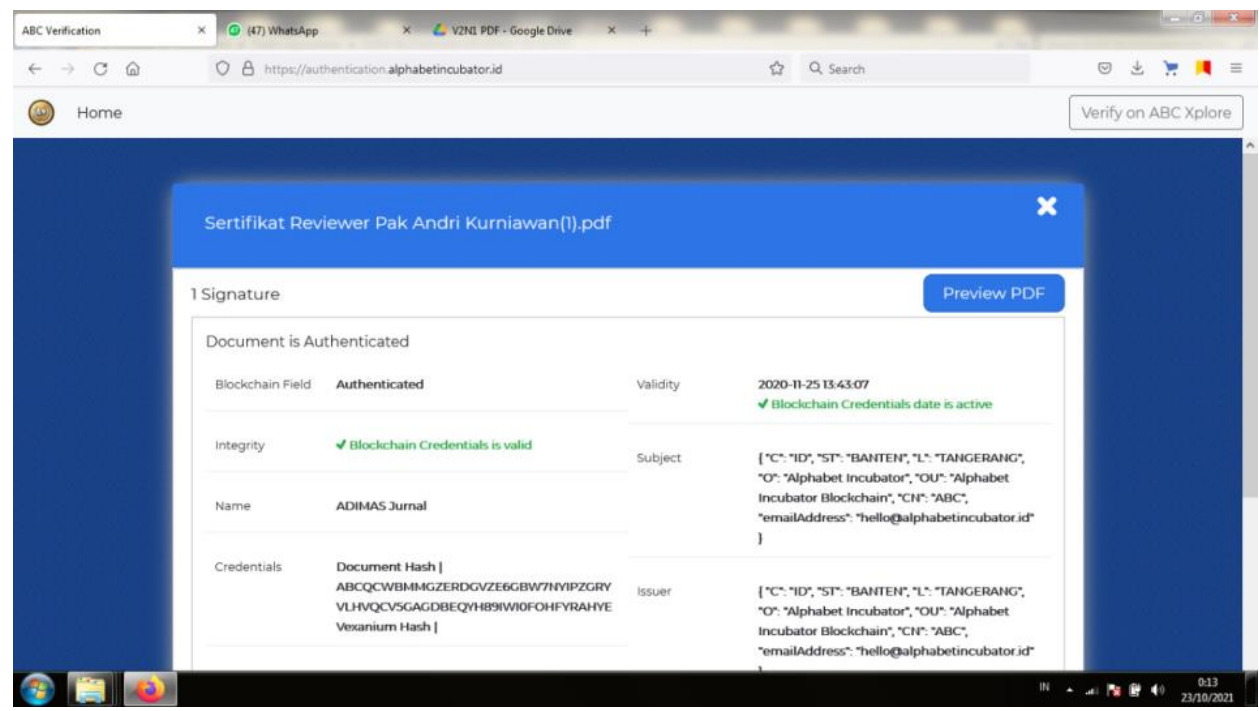

Figure 8. Reviewer letter verification

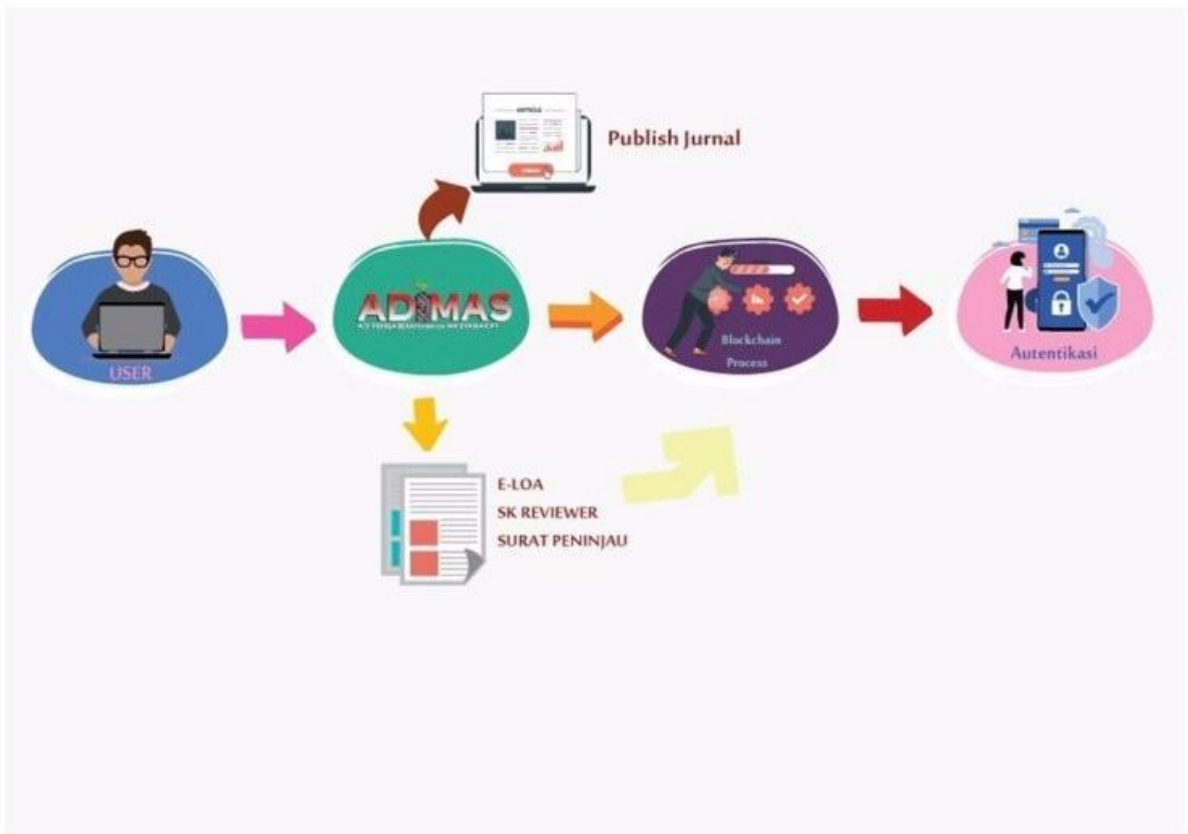

Figure 9. Blockchain workflow

In the workflow at ADIMAS, the user in question is an author who is submitting a scientific work that has been made by him, there are two activities from the journal editor and reviewer team where for the first journal editor to publish a journal that has passed the revision stage to the website, which the second is for reviewers to review journals submitted to ADIMAS. Then after doing both, namely reviewer and publishing, legal documents such as e-certificates, 
eloa, and reviewers will be issued, this document will be entered into the ABC Blockchain to apply Blockchain technology, After doing Blockchain on the document, the author or reviewer can directly check it by authenticating documents on the authentication sub menu that is already on the ADIMAS Journal website.

\section{Conclusion}

The research that has been carried out can be concluded that the application of blockchain technology can increase the security of reviewer letters that have been applied to ADIMAS with the name abc tool. From this application, it can be seen how Raharja University has been able to make new innovations in utilizing blockchain technology into the adimas website as a form of storing and securing reviewer letters so that they cannot be changed by third parties because blockchain technology (abc) already has encryption and hash codes in it, so that the reviewer's letter received can be checked for authenticity so that the parties who receive the reviewer's letter do not feel a loss. And the reviewer letter is also used by lecturers as a form of lecturer certification, therefore the use of blockchain technology avoids the circulation or buying and selling of reviewer letters to lecturers who need it as one of the certification requirements.

\section{Acknowledgements}

The existence of this journal research brought me into new things about blockchain technology and can be used as new knowledge. And the author does not forget to thank Raharja University and Alphabet Incubator for supporting this research and hopefully it can be useful for the community in adding new insights.

\section{References}

[1] Harahap, EP, Aini, Q., \& Anam, RK (2020). Utilization of Blockchain Technology on Crowdfunding Platforms. Technomedia Journal, 4(February 2), 199-210.

[2] Kosasi, S. (2020). Characteristics of Blockchain Technology in Educational Development. ADI Digital Business. Interdisciplinary J, 1(1), 87-94.

[3] Sunarya, PA, Rahardja, U., Sunarya, L., \& Hardini, M. (2020). The Role Of Blockchain As A Security Support For Student Profiles In Technology Education Systems. InfoTekJar: National Journal of Informatics and Network Technology, 4(2), 203-207.

[4] Rahardja, U., Aini, Q., Yusup, M., \& Edliyanti, A. (2020). Application of Blockchain Technology as a Security Media for E-Commerce Transaction Processes. CESS (Journal of Computer Engineering, Systems and Science), 5(1), 28-32.

[5] Prawiyogi, AG, Aini, Q., Santoso, NPL, Lutfiani, N., \& Juniar, HLJ (2021). Blockchain Education Concept 4.0: Student-Centered iLearning Blockchain Framework. JTPJournal of Educational Technology, 23(2), 129-145.

[6] Adiyanto, A., \& Febrianto, R. (2020). Authentication Of Transaction Process In Emarketplace Based On Blockchain?? technology. Aptisi Transactions on Technopreneurship (ATT), 2(1), 68-74.

[7] Rahardja, U., Lutfiani, N., \& Amelia, S. (2019). Creative Content Marketing In Scientific Publication Management In Industrial Era 4.0. Aptisi Transactions on Management (ATM), 3(2), 168-177.

[8] Yuliani, A., Nugroho, H., \& Amelia, S. (2021). Mother's Assistance in Stimulating Motor Development to Optimize Toddler Growth and Development in Pemalang Regency. ADI Community Service, 2(1), 57-61.

[9] Eka, C., Santoso, NPL, Amelia, S., \& Devana, VT (2021). Editing Software Training for Students at Raharja University. ADI Community Service, 1(2), 60-65

[10] Aini, Q., Rahardja, U., Santoso, NPL, Harahap, EPP, \& Amelia, S. Gamification Concept 
Strategy in Blockchain Technology Applications. JEPIN (Journal of Informatics Education and Research), 7(2), 219-225.

[11] Aini, Q., Rahardja, U., Tangkaw, M. R., Santoso, N. P. L., \& Khoirunisa, A. (2020). Embedding a Blockchain Technology Pattern Into the QR Code for an Authentication Certificate. Online Journal of Informatics, 5(2), 239-244.

[12] Sutandi, S. (2018). The Influence of Big Data and Blockchain Technology on the Logistics Sector Business Model With the Business Model Canvas Approach. Indonesian Logistics Journal, 2(1), 9-20.

[13] Putra, H. F., Wirawan, W., \& Penangsang, O. (2019). Application of Blockchain and Cryptography for Data Security on Smart Grid Networks. Journal of ITS Engineering, 8(1), A11-A16.

[14] Jalal, A., Suwitno, S., \& Wahyuningsih, S. E. (2018). Involvement of Notary Officials Against Unlawful Acts and Participate in Committing Crimes in Document Forgery. Journal of Deed, 5(1), 227-233.

[15] Khaerul, M., Ilyas, A., \& Muin, A. M. (2022). SYSTEM OF PROVENING DOCUMENT falsification in ELECTION CRIMINAL ACTIONS IN INDONESIA. LIVING LAW SCIENTIFIC JOURNAL, 14(1), 59-74.

[16] Sari, R. F., \& Azizah, N. (2020). QR-Code-based authenticity validation system for digital documents. JurTI (Journal of Information Technology), 4(2), 321-327.

[17] Saputra, A. J., \& Darmo, A. B. (2017). CRIMINAL LIABILITY PERFORMERS OF POPULATION DOCUMENTS IN LAW NUMBER 23 OF 2006 REGARDING POPULATION ADMINISTRATION. Legality: Journal of Law, 1(5), 203-238.

[18] Widoarjo, W., Sutopo, B., Sudaryono, E. A., Syafiqurrahman, M., \& Juliati, J. (2020). Scientific Journal Governance and Accreditation Rating Improvement Strategies. JANAKA: JOURNAL OF INDONESIAN ENTREPRENEURSHIP COMMUNITY SERVICES, 1(1), 62-73.

[19] Astuti, E., \& Isharijadi, I. (2019). Introduction of the open journal system (OJS) for student scientific publications. Journal of Community Service, 4(4), 409-414.

[20] Retnaningtyas, E., Kartikawati, E., \& Nilawati, D. (2022). ERMA EFFORTS TO INCREASE KNOWLEDGE OF PREGNANT MOTHERS THROUGH EDUCATION ABOUT THE NUTRITION NEEDS OF PREGNANT MOTHERS. ADI Community Service, 2(2), 19-24. 